\title{
Diurnal, seasonal, latitudinal and solar cycle variation of electron temperature in the topside F-region of the Indian zone ionosphere
}

\author{
M. Chamua ${ }^{1}$, P. K. Bhuyan ${ }^{1}$, P. Subrahmanyam ${ }^{2}$, and S. C. Garg ${ }^{2}$ \\ ${ }^{1}$ Department of Physics, Dibrugarh University, Dibrugarh 786004, India \\ ${ }^{2}$ RASD, National Physical Laboratory, New Delhi 110012, India
}

Received: 17 Febraury 2007 - Revised: 29 June 2007 - Accepted: 29 June 2007 - Published: 2 October 2007

\begin{abstract}
Electron temperature $T_{e}$ observed by the SROSS $\mathrm{C} 2$ satellite at equatorial and low latitudes during the low to high solar activity period of $1995-2001$ at the height of $\sim 500 \mathrm{~km}$ is investigated in terms of local time, season, latitude, solar sunspot number $R_{z}$ and $\mathrm{F} 10.7 \mathrm{~cm}$ solar flux. The satellite covered the latitude belt of $31^{\circ} \mathrm{S}-34^{\circ} \mathrm{N}$ and the longitude range of $40^{\circ}-100^{\circ} \mathrm{E}$. The average nighttime (20:00-04:00 LT) $T_{e}$ varies between $750-1200 \mathrm{~K}$ and then rises sharply in the sunrise period (04:00-06:00 LT) to the morning high from 07:00 to 10:00 LT and attains a daytime (10:00-14:00 LT) average of 1100-2300 K. The morning enhancement is more pronounced in the equinoxes. A secondary maximum in $T_{e}$ is also observed around 16:00-18:00 LT in the June solstice and in the equinoxes. Daytime electron temperature was found to be higher in autumn compared to that in spring in all latitudes. Between the solstices, the amplitude of the morning enhancement is higher in winter compared to that in summer. Both day and nighttime $T_{e}$ observed by the SROSS C2 satellite bears a positive correlation with solar activity when averaged on a shorter time scale, i.e. over the period of a month. But on a longer time scale, i.e. averaged over a year, the daytime electron temperature gradually decreases from 1995 till it reaches the minimum value in 1997, after which $T_{e}$ again continues to rise till 2001. The variations are distinctly seen in summer and in the equinoxes. The sunspot activity during solar cycle 23 was minimum in 1996 and maximum in 2000. Annual average electron temperature, therefore, appears to follow the variation of solar activity with a time lag of about one year, both at the bottom and top of solar cycle 23, indicating an inherent inertia of the ionosphere thermosphere regime to variations in solar flux.
\end{abstract}

Keywords. Ionosphere (Electric fields and currents; Equatorial ionosphere; Plasma temperature and density)

Correspondence to: $\mathrm{P}$. K. Bhuyan

(pkbhuyan@gmail.com)

\section{Introduction}

Experimental and theoretical study of electron temperature gives insight into the energy balance of the ionosphereplasmasphere regime. Characteristics of electron temperature have been studied using measurements from incoherent scatter radar (McClure, 1969, 1971; Mahajan, 1977; Oliver et al., 1991), rocket probes (Oyama et al., 1980, 1996) and satellite-based instruments (Brace et al., 1967, 1988; Clark et al., 1972; Hanson et al., 1973). Brace and Theis (1981), Triskova et al. (1996), Spenner and Plugge (1979), Truhlik et al. $(2000,2001)$ and Oyama et al. (2004) had presented empirical models of electron temperature in the ionosphere and lower plasmasphere. Richards and Torr (1986) and Watanabe et al. (1995) theoretically studied the temperature variations in the ionosphere and plsmasphere. Su et al. (1995), Oyama et al. (1996) and Balan et al. (1996a, b) used the Sheffield University Plasmasphere Ionosphere model (SUPIM) to investigate the temperature measurements made by the Hinotori and Exos D satellites. The average latitudinal and local time structure of the electron temperature was obtained at the 1000-km altitude from the Explorer 22 satellite (Brace et al., 1967). They also showed seasonal dependence of electron density and temperature. Clark et al. (1972) showed the global structure of the electron temperature in the topside ionosphere observed by the ESRO-1A satellite.

The horizontal orientation of the geomagnetic field lines at the equator and the shift between the geographic and geomagnetic equator is known to be the reason for many unique features observed in the low-latitude ionosphere, for example, the plasma fountain, equatorial ionization anomaly (Appleton, 1946), the equatorial wind and temperature anomaly (Raghavarao et al., 1991), equatorial electrojet, plasma bubbles and spread F. Hanson et al. (1973) observed the electron and ion temperatures with the Ogo 6 satellite near the magnetic equator above the $500-\mathrm{km}$ altitude. They showed that equatorial troughs of electron and ion temperatures occur in

Published by Copernicus Publications on behalf of the European Geosciences Union. 
the topside ionosphere during nighttime. They speculated that the troughs might be formed by plasma cooling by quasiadiabatic expansion caused by the inter-hemispheric transport of plasma along the magnetic flux tubes from the summer hemisphere to the winter hemisphere. This explanation was supported by Bailey et al. (1973), who showed by solving the plasma heat balance equations in the equatorial topside ionosphere that ion temperature and electron temperature troughs would result from an inter-hemispheric transport of plasma. The Japanese Hinotori satellite, which had a near circular orbit at $600 \mathrm{~km}$, provides a good but limited $\left(150 \leq \mathrm{F}_{10.7} \leq 220\right)$ database for studies of temporal and spatial variation of electron density and temperature in the topside ionosphere (Watanabe and Oyama, 1995; Su et al., 1996; Oyama et al., 1996; Balan et al., 1997). Oyama et al. (1996) observed enhanced electron temperature known as the morning overshoot in the early morning hours for a very short period of time, as measured by the Hinotori satellite. They also observed that the morning overshoot is stronger during the northern summer months and increases with an increase in solar activity. Balan et al. (1997) studied the thermal structure of the low-latitude ionosphere under equinoctial conditions at low, medium, and high solar activity using the SUPIM and Hinotori satellite observations. Their study reveals the existence of an anomaly in the plasma temperature in the topside ionosphere during the evening-midnight period. The anomaly, called the equatorial plasma temperature anomaly (EPTA), which is similar to the equatorial ionization anomaly, is characterized by a trough around the magnetic equator with crests on either side. Oyama et al. (1997) have reported the existence of an electron temperature anomaly in the low-latitude ionosphere near the $600-\mathrm{km}$ altitude during evening hours at the equinoxes under high levels of solar activity $\left(F_{10.7}>250\right)$. They have also found an association between the electron temperature anomaly and the equatorial ionization anomaly. Recently, Pavlov et al. (2004) have reported results from a comparison of measured and modelled electron densities, and electron and ion temperatures for geomagnetically quiet and moderate solar activity conditions at locations close to the geomagnetic equator and equatorial anomaly crests along the $201^{\circ}$ geomagnetic meridian. However, the database of the topside $\mathrm{F}$ region parameters over equatorial and low latitudes, particularly over the Indian subcontinent, is still inadequate for a complete understanding of the dynamics of the equatorial and low-latitude plasma. The SROSS C2 satellite provides an additional extended database for the study of electron temperature and density variations at the low-latitude topside ionosphere for a period extending from solar minimum (1995) to solar maximum (2001). Bhuyan et al. (2002a, b) have reported SROSS C2 electron temperature measurements over Indian low and equatorial latitudes using this database. Bhuyan et al. (2006) have reported the effect of solar activity on local time and seasonal variations of electron temperature measured by the SROSS $\mathrm{C} 2$ during the low to moderate solar activity period from
1995 to 1998 over the Indian subcontinent and compared the data with that of the International Reference Ionosphere (IRI2001) model.

In this paper, we present the results of the study of the effect of solar cycle variation on the diurnal, latitudinal and seasonal variation of $T_{e}$ within $\pm 10^{\circ}$ of the geomagnetic equator over India during the period of low (1995) to high (2001) solar activity using the SROSS C2 data. During this period, the F10.7 cm solar flux varied from the minimum of $\sim 72$ in 1996 to the maximum of $\sim 179$ in 2000.

\section{Results}

\subsection{Diurnal, seasonal and latitudinal variation of $T_{e}$}

The electron temperature measured by the SROSS C2 during the period January 1995 to July 2001 has been studied over three latitudes: $\pm 10^{\circ}$ of the geomagnetic equator and directly over the geomagnetic equator. For each latitude the data are grouped into bins of $\pm 2.5^{\circ}$ in latitude and $1 \mathrm{~h}$ in local time. Figure 1 shows the scatter plot of $T_{e}$ against local time over $10^{\circ} \mathrm{N}$ of the geomagnetic equator for the June solstice (May, June, July and August), December solstice (November, December, January, February) and the equinoxes (March, April, September, October). The highest value of $T_{e}$ was observed in the period 04:00 to 06:00 LT irrespective of latitude and season of observation. The morning peak value averaged for the four months of a season varied from $\sim 3600 \mathrm{~K}$ in 1995 to $\sim 2600 \mathrm{~K}$ in 2000 in summer. The daytime (10:0014:00 LT) average electron temperature also varied from a low value of $\sim 1400 \mathrm{~K}$ observed in the year 1998 to a high value of $\sim 2400 \mathrm{~K}$ in the year 1995 . The afternoon enhancement is maximum in the year $1995(\sim 2700 \mathrm{~K})$ and decreases with the increase in solar activity. The nighttime (20:0004:00 LT) $T_{e}$ increases from $\sim 800 \mathrm{~K}$ in 1996 to $\sim 1100 \mathrm{~K}$ in 2001. In winter, the average value of the morning peak is $\sim 3400 \mathrm{~K}$ in 1996 and $\sim 3300 \mathrm{~K}$ in 2001 . The noontime electron temperature is $\sim 2200 \mathrm{~K}$ in 1996 and $\sim 1750 \mathrm{~K}$ in 2001. The nighttime $T_{e}$ increases from a value of $\sim 800 \mathrm{~K}$ in 1996 to $\sim 1000 \mathrm{~K}$ in 2001 . In the equinoxes, the morning peak electron temperature varies from $\sim 2950 \mathrm{~K}$ (1999) to $\sim 3600 \mathrm{~K}$ (1998) in its average value and the mean daytime temperature varies from $\sim 1200 \mathrm{~K}(1997)$ to $\sim 1900 \mathrm{~K}$ (1995). The afternoon enhancement is most prominent in the year $1995(\sim 2000 \mathrm{~K})$ and decreases with the increase in solar activity. The nighttime $T_{e}$ is minimum $(\sim 800 \mathrm{~K})$ in the year 1997 and maximum $(\sim 1150 \mathrm{~K})$ in the year 2001 . Average daytime $T_{e}$ in winter was found to be higher than that in summer by $\sim 200 \mathrm{~K}$ to $\sim 400 \mathrm{~K}$ during 1996 to 2000 . In the years 1995 to 2001 , the average daytime $T_{e}$ exceeds that measured in winter.

Figure 2 shows the scatter plot of $T_{e}$ over the geomagnetic equator in three seasons and for the period 1995-2001. In summer, the morning peak goes up to $\sim 5000 \mathrm{~K}$ in the year 


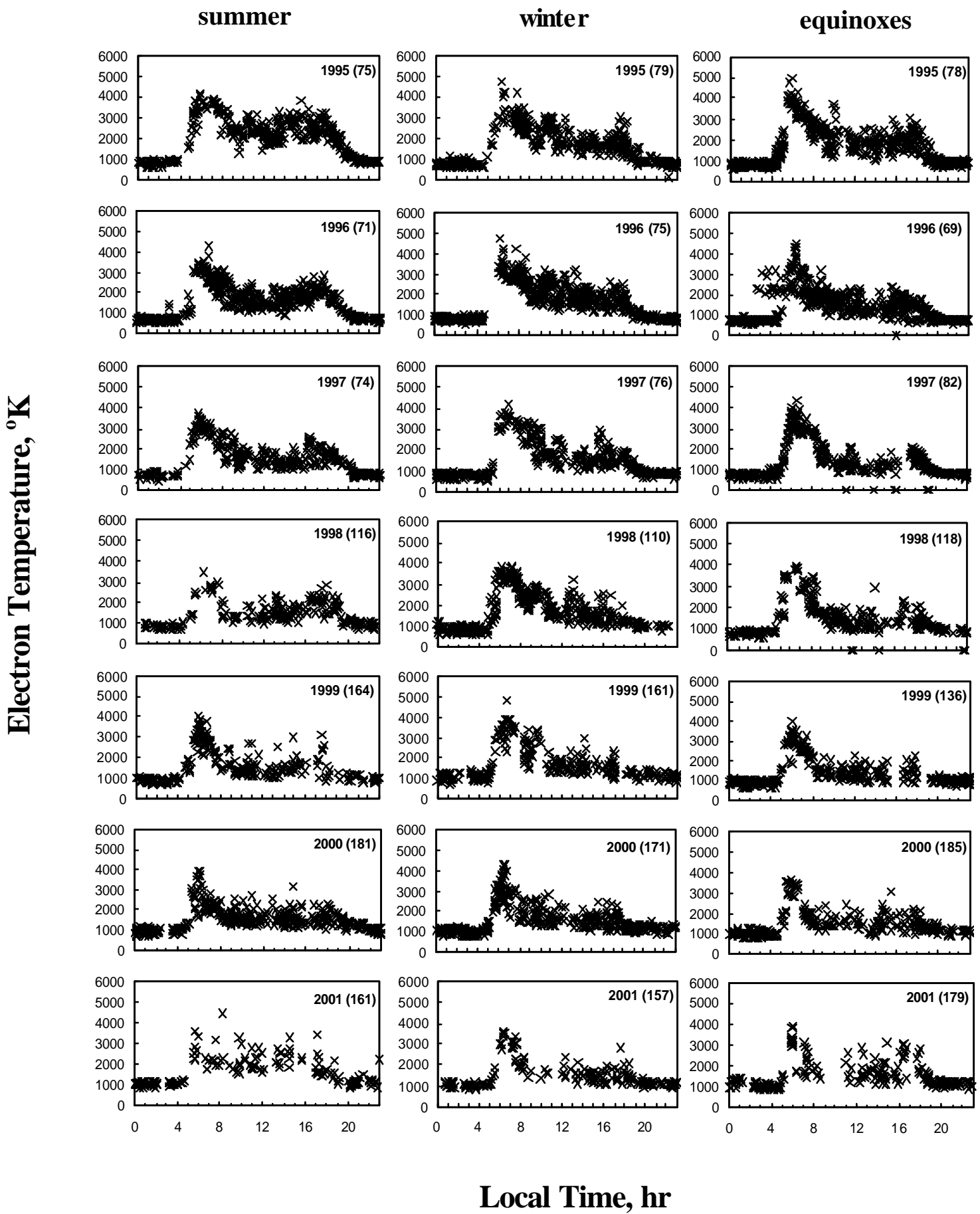

Fig. 1. Scatter plot showing the diurnal and seasonal variations of $T_{e}$ over the years 1995 to 2001 measured by the SROSS C2 within $\pm 2.5^{\circ}$ of $10^{\circ} \mathrm{N}$ geomagnetic latitude. The figures within the parentheses indicate the average $\mathrm{F} 10.7 \mathrm{~cm}$ solar flux.

1995 and the average value of the peak electron temperature during the morning hour varies from $\sim 2650 \mathrm{~K}$ to $\sim 4000 \mathrm{~K}$ during 1995-2001. The temperature at noon varies from $\sim 1400 \mathrm{~K}$ in 1997 to $\sim 2000 \mathrm{~K}$ in 2001 . The average nighttime $T_{e}$ increases from $\sim 750 \mathrm{~K}$ in 1996 to $\sim 1200 \mathrm{~K}$ in 2001 . The afternoon peak is highest in the year $1995(\sim 2400 \mathrm{~K})$ and decreases with the increase in solar activity. With the increase in solar activity the daytime $T_{e}$ increases and the afternoon enhancement disappears towards the high solar activity years of 2000-2001. In winter the morning enhancement varies from $\sim 2700 \mathrm{~K}$ to $\sim 3900 \mathrm{~K}$ in its average value. At noon the temperature varies from $\sim 1200 \mathrm{~K}$ to $\sim 1700 \mathrm{~K}$. 

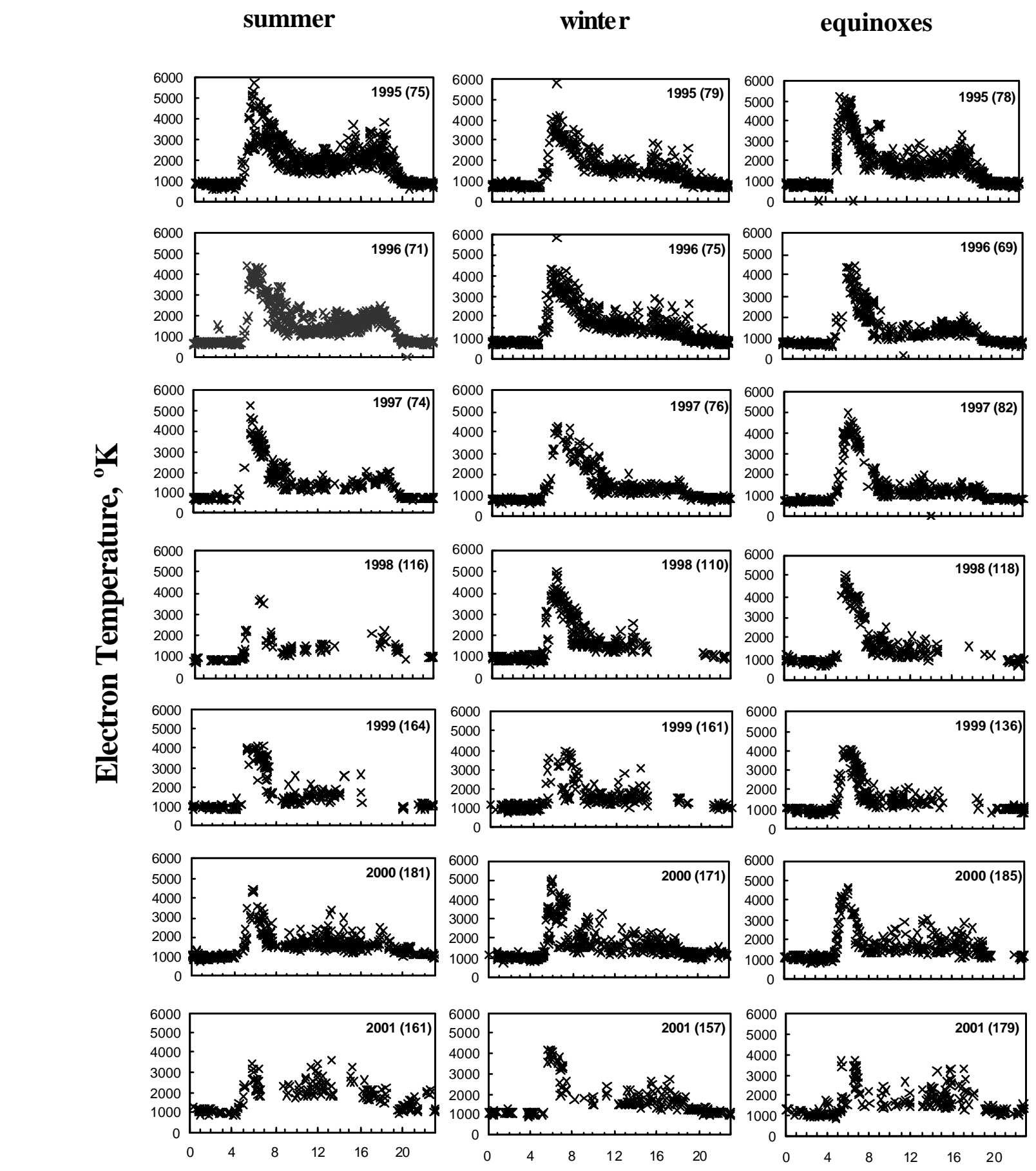

\section{Local Time, hr}

Fig. 2. Scatter plot showing the diurnal and seasonal variations of $T_{e}$ over the years 1995 to 2001 measured by the SROSS C 2 within $\pm 2.5^{\circ}$ of $10^{\circ} \mathrm{N}$ geomagnetic latitude. The figures within the parentheses indicate the average $\mathrm{F} 10.7 \mathrm{~cm}$ solar flux.

The average nighttime $T_{e}$ increases from $\sim 800 \mathrm{~K}$ in 1997 to $\sim 1100 \mathrm{~K}$ in 2001 . For the equinox the average morning peak electron temperature is highest in the year $1998(\sim 4200 \mathrm{~K})$ and lowest in the year $2001(\sim 3000 \mathrm{~K})$. The noontime $T_{e}$ increases from $\sim 1150 \mathrm{~K}$ in the year 1996 to $\sim 1850 \mathrm{~K}$ in the year 2001. The nighttime $T_{e}$ varies from $\sim 750 \mathrm{~K}$ in 1996 to 


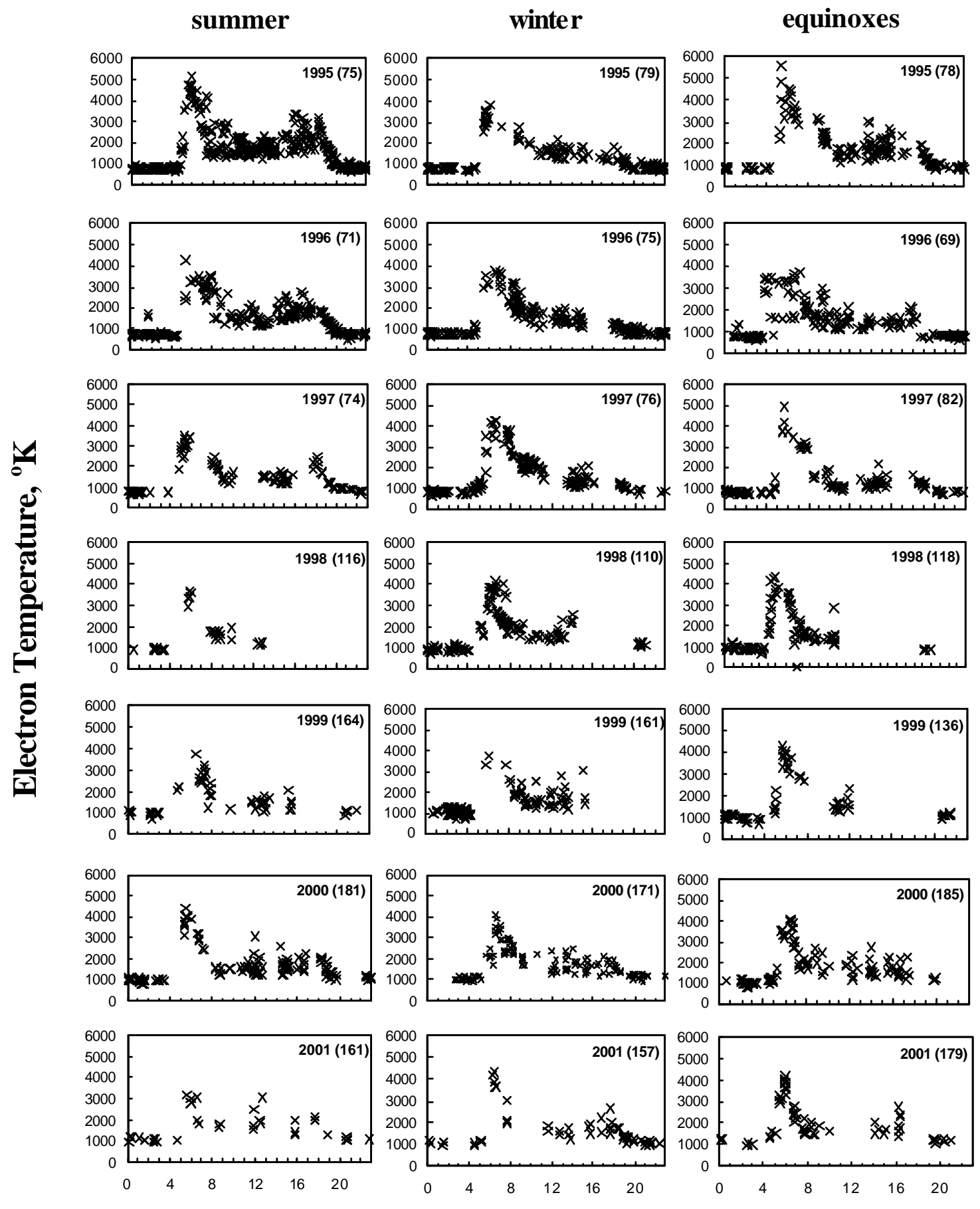

\section{Local Time, $\mathrm{hr}$}

Fig. 3. Scatter plot showing the local time variation of the electron temperature measured by the SROSS $\mathrm{C} 2$ within $\pm 2.5^{\circ}$ of $10^{\circ} \mathrm{S}$ magnetic latitude in the three seasons from 1995 to 2001 . The average F10.7 cm solar flux is shown within the parentheses.

$\sim 1200 \mathrm{~K}$ in 2001 . Except in winter the daytime $T_{e}$ increases by $\sim 700 \mathrm{~K}$ to $\sim 1000 \mathrm{~K}$ in the equinoxes and summer during the period. The afternoon enhancement in the equinoxes is highest in the year 1995 ( $\sim 2100 \mathrm{~K})$ and it disappears towards the high solar activity. It should be noted that the morning peak electron temperature decreases from the year 

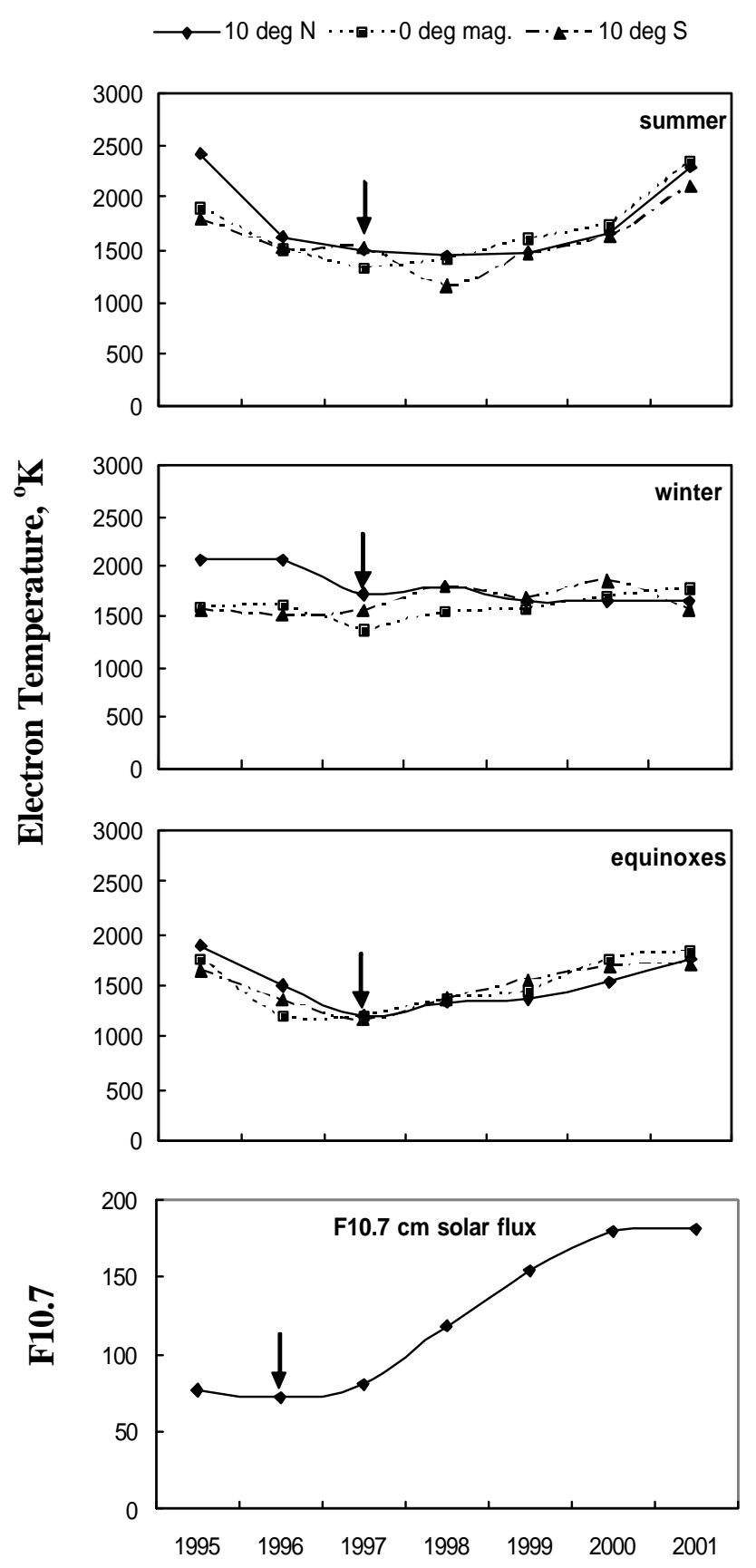

\section{Years}

Fig. 4. Variation of mean daytime (10:00-14:00 LT) $T_{e}$ and F10.7 cm solar flux averaged for each year of observation from 1995 to 2001. The maximum standard error for the data points is less than 3 percent.

of minimum solar activity (1996) to the year of maximum solar activity (2001) in all three seasons.

In Fig. 3 the diurnal and seasonal variations of $T_{e}$ (all data) over $10^{\circ} \mathrm{S}$ are shown. In summer the average value of the morning peak electron temperature varied from a minimum of $\sim 2900 \mathrm{~K}$ in 2001 to a maximum of $\sim 3800 \mathrm{~K}$ in the year 1995. The average daytime $T_{e}$ in this season also varied between $\sim 1150 \mathrm{~K}$ in 1998 and $\sim 2100 \mathrm{~K}$ in 2001 . The average nighttime temperature varies from $\sim 790 \mathrm{~K}$ in 1996 to $\sim 1070 \mathrm{~K}$ in 2001 . An afternoon enhancement has been observed in this season. Maximum enhancement of $\sim 700 \mathrm{~K}$ above the average daytime $T_{e}$ occurred in the year 1995 . The amplitude of the afternoon enhancement in $T_{e}$ was found to decrease with an increase in solar activity. In winter, the minimum for the average morning $T_{e}$ was observed in the year $2000(\sim 2900 \mathrm{~K})$ while in rest of the years it remained above $3500 \mathrm{~K}$ and reached a high of $\sim 3900 \mathrm{~K}$ in 1997 and 2001. The average daytime electron temperature varied by $\pm 75 \mathrm{~K}$ from $1550 \mathrm{~K}$ in winter. Nighttime $T_{e}$ was lowest $(\sim 800 \mathrm{~K})$ in the year 1996 and highest $(\sim 1100 \mathrm{~K})$ in 2000 . No afternoon enhancement of $T_{e}$ was observed in this season. In the equinoxes, the measured minimum value of morning $T_{e}$ was $\sim 2600 \mathrm{~K}$ in the year 1996 while a maximum of $\sim 4100 \mathrm{~K}$ was observed in 1997. The average daytime electron temperature varied between $\sim 1200 \mathrm{~K}$ and $\sim 1700 \mathrm{~K}$. Nighttime $T_{e}$ was lowest in the year 1997 and highest in 2001, with values of $\sim 800 \mathrm{~K}$ and $\sim 1200 \mathrm{~K}$, respectively. A secondary enhancement of $T_{e}$ in the afternoons of the equinox was observed, the magnitude of which decreased with an increase in solar activity. The data points are less over $10^{\circ} \mathrm{S}$ of the geomagnetic equator.

The decrease in electron temperature from the morning high to the daytime steady level is slower over $10^{\circ} \mathrm{N}$ than over the magnetic equator and $10^{\circ} \mathrm{S}$ in all three seasons and in low to moderate solar activity period. The morning enhancement is more pronounced in the equinoxes over all three latitudes. The amplitude of the morning peak is higher in winter compared to that in summer over $10^{\circ} \mathrm{S}$ and $10^{\circ} \mathrm{N}$ of the geomagnetic equator. Daytime $T_{e}$ is found to be higher in autumn compared to that in spring over all three latitudes.

\subsection{Solar cycle variation}

In Fig. 4 the daytime electron temperature and sunspot number averaged over the years have been plotted. The standard errors $(\sigma / \sqrt{ } \mathrm{N})$ for the averages varied from less than $1 \%$ to $3 \%$. Marginally higher errors are seen in certain cases of $10^{\circ} \mathrm{S}$ magnetic latitude. The daytime electron temperature gradually decreases from 1995 till it reaches the minimum value in 1997, after which $T_{e}$ again continues to rise till 2001. The variations are distinctly seen in summer and in the equinoxes. The sunspot activity during solar cycle 23 was minimum in 1996 and maximum in 2000. The annual average electron temperature thus appears to follow the variation of solar activity with a time lag of about one year, both at the bottom and top of solar cycle 23, indicating inertia of the ionosphere thermosphere regime to variations in solar flux.

The effect of the variation of solar activity on electron temperature in a shorter time scale is studied by plotting 

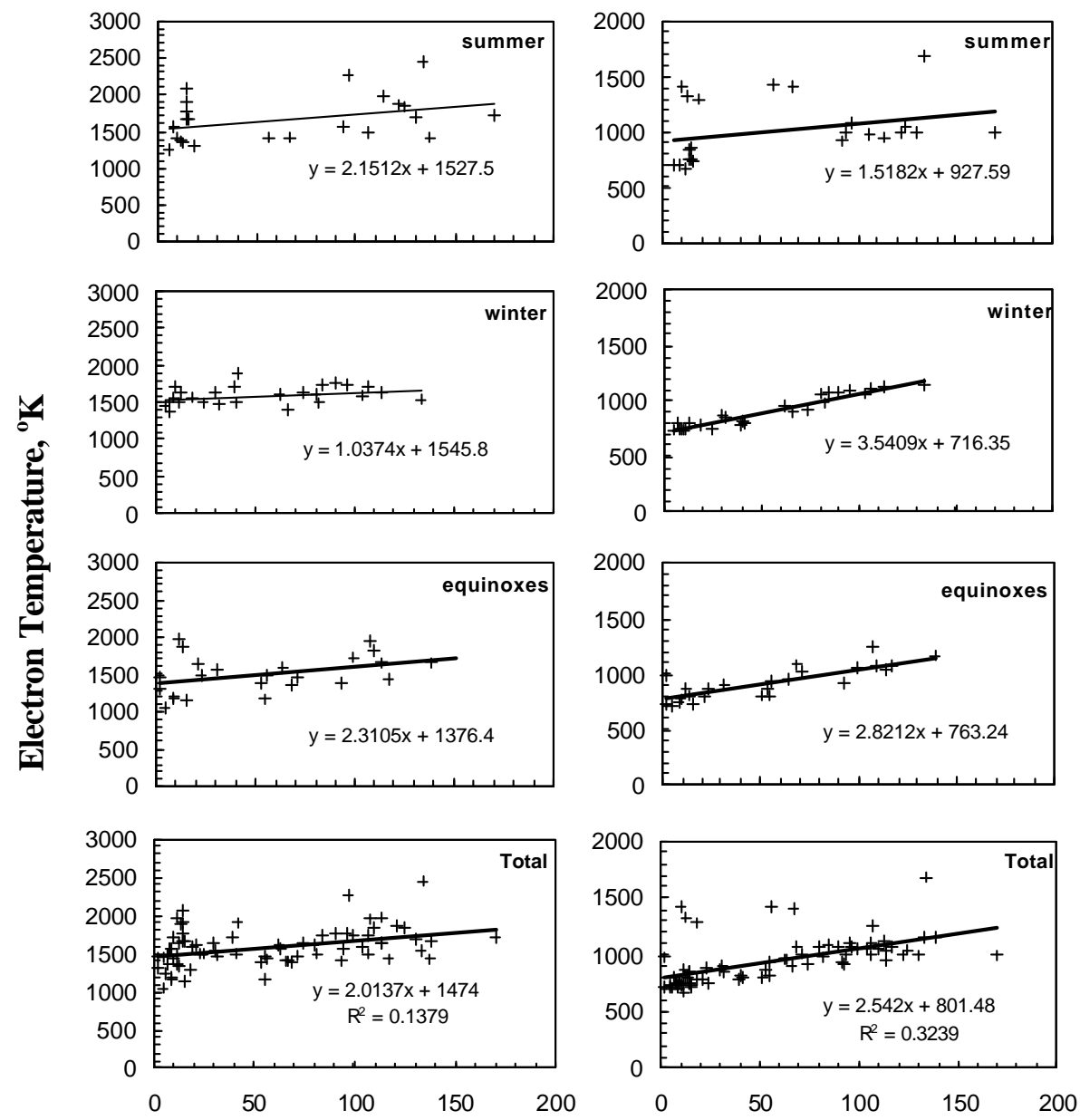

\section{Sunspot number $\left(\mathbf{R}_{\mathbf{z}}\right)$}

Fig. 5. Variation of average daytime (left panel) and nighttime (right panel) electron temperatures observed by the SROSS C2 satellite with $R_{z}$ over the magnetic latitude. Standard error for the data points varies within one to three percent.

the monthly mean daytime (10:00-14:00 LT) and nighttime (22:00-02:00 LT) measured electron temperature within the region $\pm 10^{\circ}$ magnetic latitude against the monthly mean sunspot number $R_{z}$, shown in Fig. 5. The maximum standard error of the data points is $\sim 3 \%$ of the mean. Sunspot number varied from the minimum of 0.9 in October 1996 to the maximum of 170 in July 2000. The $T_{e}$ versus $R_{z}$ plots are shown separately for the three seasons and for all data combined. Electron temperature bears a positive correlation with solar activity in all three seasons, both during daytime and nighttime. The relationship between $T_{e}$ and $R_{z}$ at the altitude of $\sim 500 \mathrm{~km}$ can be expressed from the least-squares fit as

$T_{e(\text { day })}=2.0137 R_{z}+1474$

$T_{e(\text { night })}=2.542 R_{z}+801.5$.
The rate of increase in $T_{e}$ with sunspot activity is faster during the nighttime than during the day. R-squared values of Eqs. (1a) and (1b) are 0.1379 and 0.3239 , respectively. The trend line is closer to the actual value at night.

The response of electron temperature to solar activity is further investigated by plotting the average daytime and nighttime electron temperature against the $\mathrm{F}_{10.7} \mathrm{~cm}$ solar flux, as shown in Fig. 6. The standard errors are within 3\% for nearly all data points. Electron temperature increases linearly with the increase in $\mathrm{F}_{10.7} \mathrm{~cm}$ solar flux, both during the day and night and in all seasons. The linear relationship is expressed by

$T_{e(\mathrm{day})}=1.986 F_{10.7}+1358$

$T_{e(\text { night })}=2.5216 F_{10.7}+653$. 

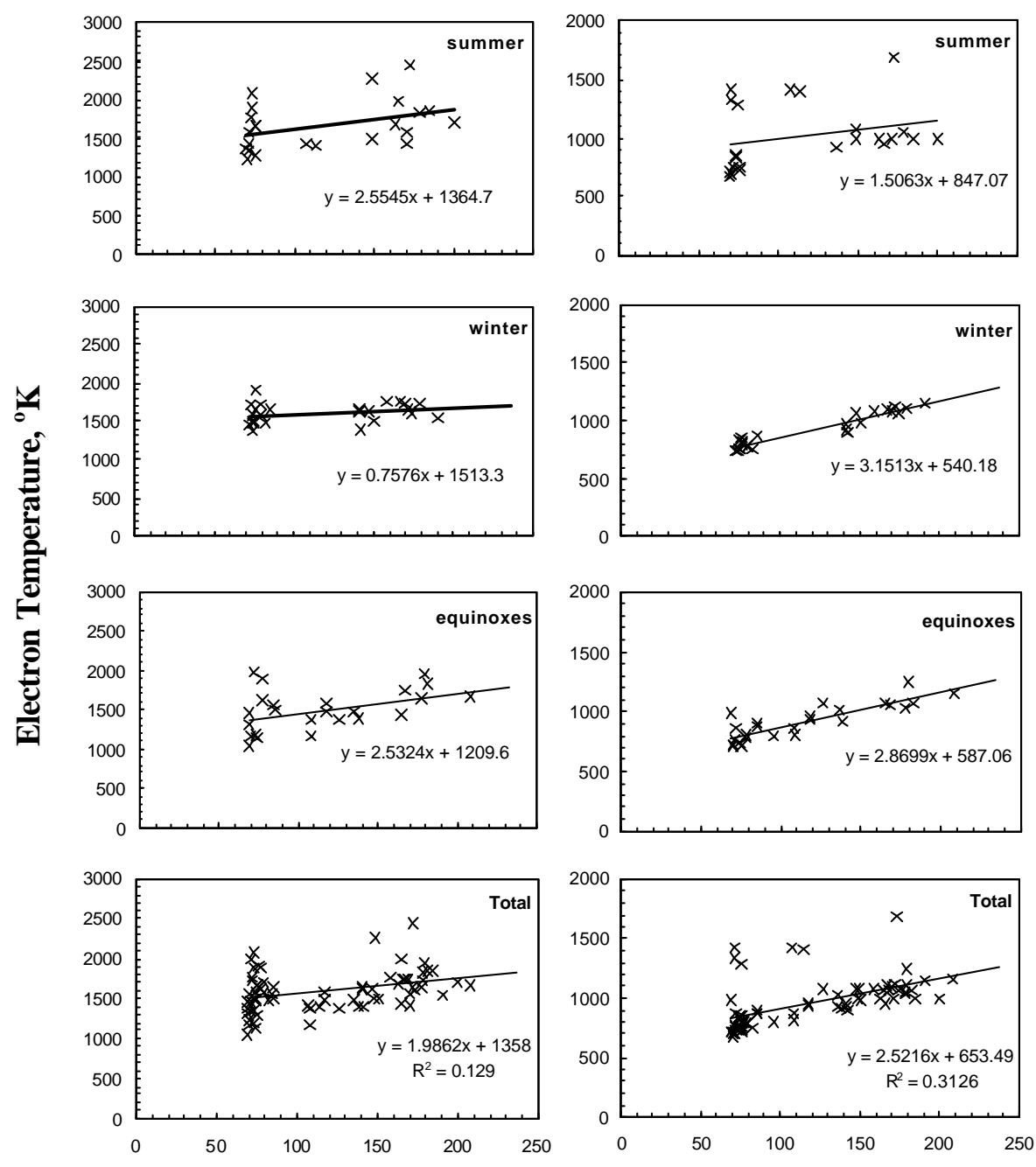

\section{F10.7 cm solar flux}

Fig. 6. Variation of averaged daytime (left panel) and nighttime (right panel) electron temperatures observed by the SROSS C2 satellite with F10.7 over the magnetic equator.

As with the sunspot number, the rate of increase in the electron temperature with the increase in solar $\mathrm{F}_{10.7} \mathrm{~cm}$ solar flux is higher at night compared to that during daytime. The $\mathrm{R}$ squared values 0.129 for Eq. (2a) and 0.3126 of Eq. (2b) reveal that the estimated values are closer to the actual values at night. Oyama (1994) had obtained the following relationship between nighttime $T_{e}$ at $600 \mathrm{~km}$ and $\mathrm{F}_{10.7}$ and $R_{z}$ :

$T_{e(\min )}=1.258 F_{10.7}+835$

$T_{e(\min )}=1.16 R_{z}+907$.

A comparison of Eqs. (1), (2) and (3) reveals that the average electron temperature at $600 \mathrm{~km}$ measured by the Hinotori during the night is higher than that at $500 \mathrm{~km}$, as measured by the SROSS C2 satellites. However, the positive response of electron temperature to solar activity is found to be faster at $500 \mathrm{~km}$ compared to that $100 \mathrm{~km}$ above. Pandey and Mahajan (1985) observed that the electron temperature is directly related to solar activity at $300 \mathrm{~km}$. They found that as the solar activity increases electron temperature also increases and vice versa. Brace and Theis (1981), on the other hand, found that at the altitude of $300 \mathrm{~km}$, ISIS satellite measured daytime $T_{e}$ shows a significant decrease with an increase in solar flux, whereas at the altitude of $3000 \mathrm{~km}, T_{e}$ does not appear to vary with solar activity during the solar maximum period of solar cycle 20 . According to them, the reduction in electron temperature with an increase in F10.7 might have reflected the enhanced cooling rate associated with higher $\mathrm{F}$ region $\mathrm{O}^{+}$ densities. The nighttime electron temperature at $300 \mathrm{~km}$ was found to increase with F10.7, reflecting an increase in neutral 

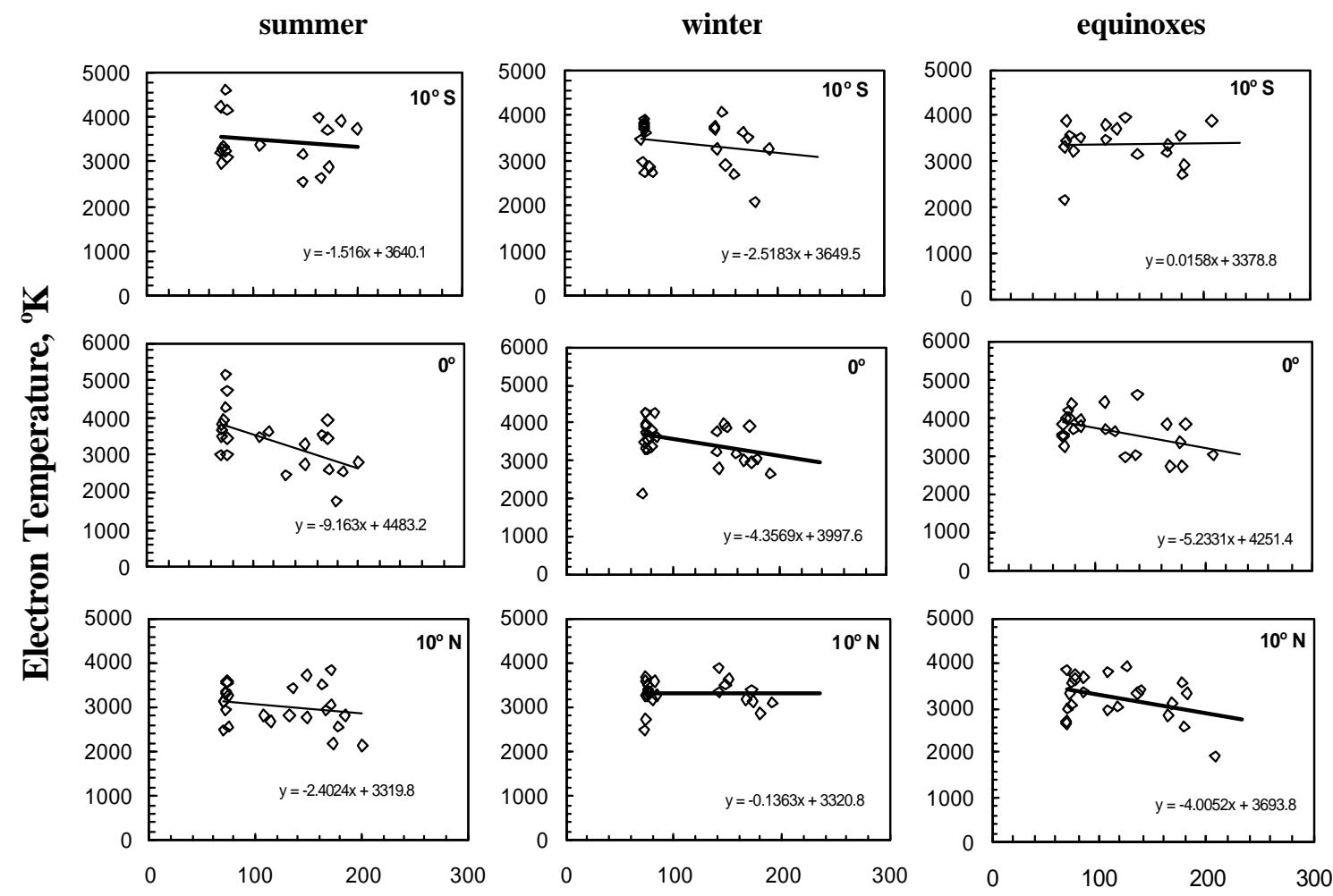

F10.7 cm solar flux

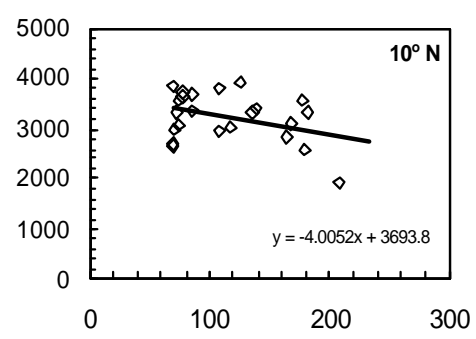

Fig. 7. Plot of average morning peak electron temperature observed within $10^{\circ} \mathrm{N}$ and $10^{\circ} \mathrm{S}$ magnetic latitudes with $\mathrm{F} 10.7 \mathrm{~cm}$ solar flux.

gas temperature. The nighttime positive correlation of $T_{e}$ with F10.7, found by Brace and Theis (1981), is in contrast with earlier measurements reported by Brace et al. (1967). Mahajan and Pandey (1979) found that $T_{e}$ at $1000 \mathrm{~km}$ increased with solar activity between 1965 and 1969. Using SROSS C2 data for the low to moderate solar activity period of 1995-1998, Bhuyan et al. (2006) had recently reported a positive correlation between electron temperature and F10.7 for both daytime and nighttime at $500 \mathrm{~km}$ over $10^{\circ} \mathrm{N}$ of the geomagnetic equator.

The amplitude of the morning and afternoon enhancements in $T_{e}$ varies with solar activity. In Fig. 7, the peak morning temperature observed over $\pm 10^{\circ}$ magnetic latitude and the geomagnetic equator are plotted against the $\mathrm{F}_{10.7} \mathrm{~cm}$ solar flux. The figure indicates that the morning peak temperature decreases with an increase in solar activity irrespective of season and solar activity. The rate of decrease in the electron temperature with the increase in solar flux is slow in winter compared to that in either equinox or summer.

The peak temperature observed during the period of afternoon enhancement in summer and the equinox exhibits a mixed response to the change in solar activity. While peak afternoon $T_{e}$ in summer decreases with an increase in solar flux, in the equinox (Fig. 8) the trend is slightly positive.

\section{Discussion}

The morning enhancement observed shortly after sunrise is the most important feature of the diurnal variations of electron temperature at equatorial and low latitudes. In the post sunrise hour the electron temperature increases by about $1500 \mathrm{~K}-3500 \mathrm{~K}$ from its nighttime value. Dalgarno and McElroy (1965) predicted that such an effect would be caused by a mere rapid morning buildup of neutral gas density rather than a buildup of ionization density, with a resulting lag between heating and cooling rates. DaRosa (1966) calculated the time dependent behaviour of $T_{e}$ during the morning hours. The first experimental evidence of the morning enhancement in $T_{e}$ was reported by Evans (1965) followed by McClure (1971), Clark et al. (1972) and many workers afterwards. Oyama et al. (1996) reported that the electron temperature at the altitude of $600 \mathrm{~km}$ rises in the morning from its nighttime level of $\sim 1200 \mathrm{~K}$ to $\sim 4000 \mathrm{~K}$ within $\pm 30^{\circ}$ magnetic latitudes. They observed that the morning enhancement is strong during northern summer months and grows with an increase in solar activity. Present observations with the SROSS C2 have indicated that the morning enhancement weakens with increase in solar activity. Enhancement in morning $T_{e}$ is due to photoelectron heating. Photoelectron production begins at sunrise through 

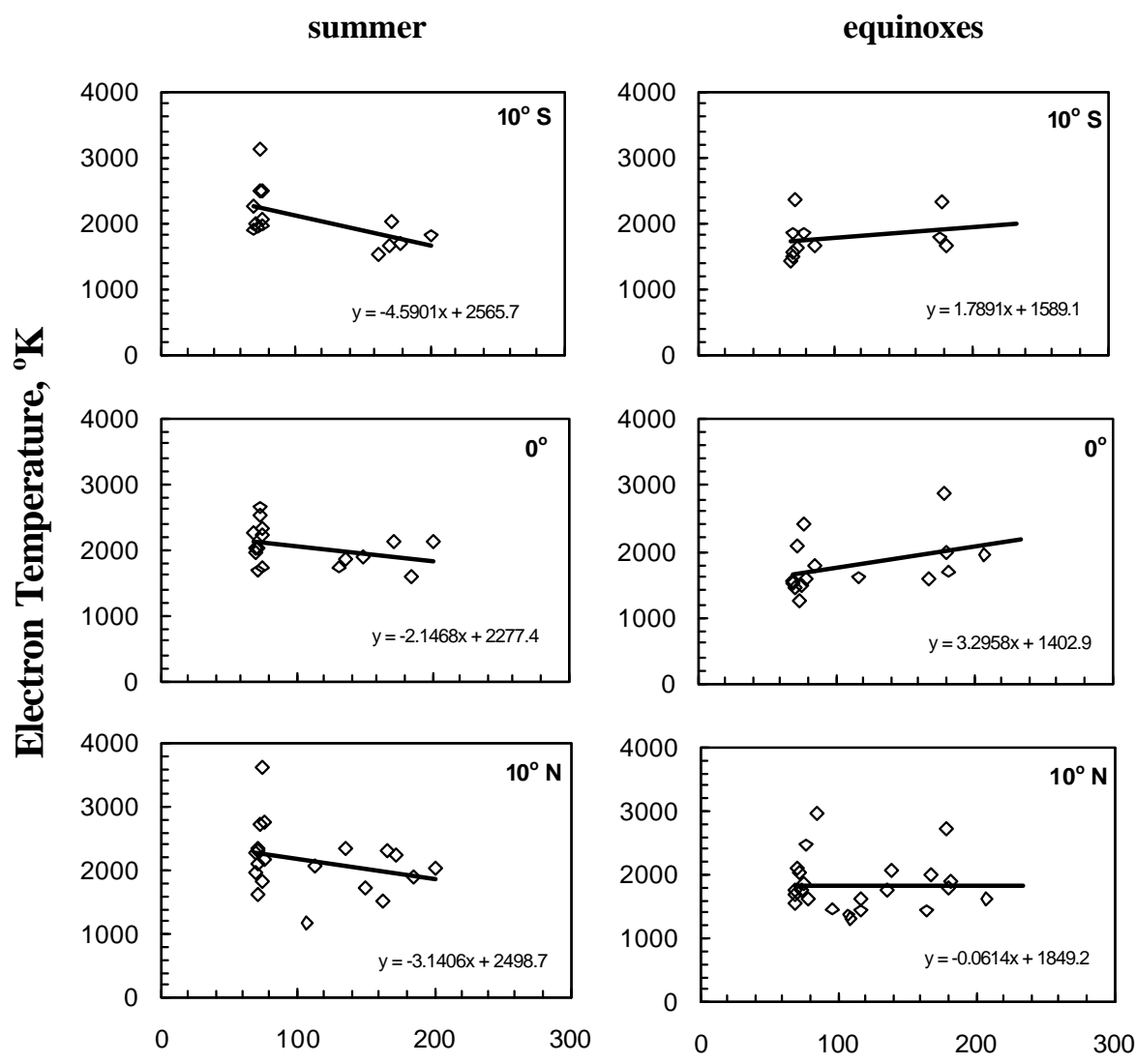

F10.7 cm solar flux

Fig. 8. Variation of afternoon peak electron temperature observed within $10^{\circ} \mathrm{N}$ to $10^{\circ} \mathrm{S}$ magnetic latitudes with $\mathrm{F} 10.7 \mathrm{~cm}$ flux.

the ionization of neutral particles. As the photoelectrons share their high energy with the ambient electrons, the electron temperature increases; the increase is rapid in the early morning hours due to low electron density. From the theoretical simulation of observed $T_{e}$ enhancements, Oyama et al. (1996) have shown that intense morning enhancement of $T_{e}$ observed over the equator is due to a reduction in electron density caused by the downward drift of plasma, which usually occurs in the morning hours. After sunrise the temperature decreases as electron density increases and energy is shared between more electrons. The daytime valley is the result of the balance between the electron heating and cooling processes. Though near noon electron heating by solar EUV is maximum, it is more than offset by electron cooling resulting from the higher noontime electron density. The latitudinal variation of morning and daytime electron temperature is influenced by the latitudinal variation of electron density. The electron temperature also increases in the afternoon in the same way as in the morning of the June solstice. Watanabe and Oyama (1996) have reported enhancement of electron temperature at $\sim 18: 00 \mathrm{LT}$ in the mid lat- itudes from measurements of the Hinotori satellite during 1981-1982. From a three- dimensional computer simulation carried out to study the measurements made by the Hinotori satellite, Watanabe et al. (1995) have found that the afternoon enhancement in the mid latitudes comes from the balance of heating and cooling. The enhancement is influenced by meridional neutral wind. Around the equatorial anomaly region the electron temperature in the topside $F$ region increases in the evening because of the competing effects of plasma cooling and plasma transport. Pavlov et al. (2004) have conducted a modelling study of electron and ion temperatures over Akita, Kokubunji, Yamagawa, Okinawa, Chung-Li, Manila, Vanimo and Darwin ionospheric sounders and over the MU radar at Shigaraki. Their study reveals that the diurnal variations of $T_{e}$ are characterised by morning and evening peaks above the Yamagawa, Kokubunji and Akita ionosonde stations and over the MU radar, while there is only a morning peak in $T_{e}$ over the Darwin, Vanimo, Manila, Chung-Li and Okinawa ionosonde stations. There is rapid heating of daytime electrons by photoelectrons and the difference between electron and ion temperatures increases 
after sunrise because daytime electron density $N_{e}$ and the resulting electron cooling are compared more to that which occurs at night. Increased $N_{e}$ causes decrease in $T_{e}$ after the abrupt morning enhancement. The nighttime and morning $\boldsymbol{E} \times \boldsymbol{B}$ drift moves the plasma from middle to low geomagnetic latitudes, and the plasma diffuses downward along the magnetic field lines. The $N m \mathrm{~F} 2$ reduction caused by the increase in the loss rate of $\mathrm{O}^{+}\left({ }^{4} \mathrm{~S}\right)$ ions is stronger than the enhancement in $N m \mathrm{~F} 2$ caused by the plasma inflow. Thus, the nighttime and morning downward $\boldsymbol{E} \times \boldsymbol{B}$ drift caused the decrease in $N m \mathrm{~F} 2$ close to sunrise, resulting in an increase in the morning $T_{e}$ peak. The nighttime and morning downward $\boldsymbol{E} \times \boldsymbol{B}$ drift becomes more effective in lowering $N_{e}$ by lowering the geomagnetic latitude, with a consequent increase in the morning $T_{e}$ peak close to the equator. The nighttime neutral wind reduces the morning $T_{e}$ through an increase in $N_{e}$ but it becomes less effective towards the equator. On the other hand, a poleward wind in the morning time period decreases the F2 peak height, $h m \mathrm{~F} 2$, causing an increase in the loss rate of $\mathrm{O}^{+}\left({ }^{4} \mathrm{~S}\right)$ ion at $h m \mathrm{~F} 2$, a decrease in $N m \mathrm{~F} 2$ and thus an enhancement in $T_{e}$. Their study further suggests that a poleward wind forces the F2 layer to descend to low altitudes of heavy chemical $\mathrm{O}^{+}\left({ }^{4} \mathrm{~S}\right)$ ion losses, reducing $N_{e}$ to low values before sunset. Due to the poleward wind, the rate of decrease in $N m \mathrm{~F} 2$ due to declining solar radiations becomes strong producing a pronounced decrease in the thermal electron cooling rate and the resulting increase in the evening $T_{e}$ peak. The effect of the plasma drift due to the neutral wind on $N_{e}$ weakens towards the equator, resulting in a decrease in magnitude or the disappearance of the evening peak of $T_{e}$ near the equator. Balan et al. (1997) observed that adiabatic expansion of the plasma and an increase in plasma density caused by prereversal strengthening of the upward vertical $\boldsymbol{E} \times \boldsymbol{B}$ drift cause the temperature trough around the equator while the combined effect of the reverse plasma fountain and nighttime plasma cooling produces the temperature crests.

The major physical processes that control the F2 region electron temperature are photoelectron heating and electron cooling due to loss in collisions with the ambient ions. The increase in solar activity gives rise to the increase in solar energy with the consequent escalated production of photoelectrons and thus the increase in the electron heating rates. The increased heating rate leads to elevated electron temperature. The increase in solar activity also results in higher values of ion concentration, which gives rise to an increased cooling rate, resulting in a decrease in $T_{e}$ (Schunk and Nagy, 1978). Therefore, the solar activity increase produces a net $T_{e}$ that is a balance between the above two processes. The observed time lag between the solar cycle and electron temperature variation might possibly be due to an inherent inertia of the ionosphere thermosphere regime, which leads to a nonlinear variation of ionospheric parameters with solar flux.

\section{Conclusion}

The electron temperatures measured by the SROSS C2 satellite from 1995 to 2001 have been used to investigate the effect of solar activity on its diurnal and seasonal variation over $\pm 10^{\circ}$ of the geomagnetic equator and directly over the geomagnetic equator. Results show that electron temperature at the average height of $500 \mathrm{~km}$ varies from year to year, with season and with latitude. For example, the nighttime $T_{e}$ varies from $750 \mathrm{~K}$ to $1200 \mathrm{~K}$, the morning enhancement varies from $2500 \mathrm{~K}$ to $4100 \mathrm{~K}$. The average daytime $T_{e}$ varies from $1100 \mathrm{~K}-2300 \mathrm{~K}$. Similarly, the afternoon enhancement varies from $1700 \mathrm{~K}$ to $2700 \mathrm{~K}$. The variation of day and nighttime electron temperature can be mainly attributed to the influence of solar activity variation, as monthly mean $T_{e}$ exhibits a positive correlation with solar activity measured in terms of sunspot number $R_{z}$ and $\mathrm{F} 10.7 \mathrm{~cm}$ solar flux, both during the day and night. However, on a longer time scale, i.e. averaged over a year, the daytime electron temperature follows the annual average solar flux with a time lag of one year at the minimum of the solar cycle 23 .

Acknowledgements. Authors thank all the scientists who were involved in the SROSS C2 project for their untiring efforts that led to successful eight year active life of the satellite and the RPA payload on board. M. Chamua is grateful to the Department of Science and Technology, Govt. of India for providing financial assistance under the scheme "SERC FAST TRACK PROPOSALS FOR YOUNG SCIENTISTS" to pursue this work at Dibrugarh University.

Topical Editor M. Pinnock thanks S. Watanabe and another anonymous referee for their help in evaluating this paper.

\section{References}

Appleton, E. V.: Two anomalies in the ionosphere, Nature, 157, 691, 1946.

Bailey, G. J., Moffett, R. J., Hanson, W. B., and Sanatani, S.: Effect of interhemispheric transport on plasma temperature at low latitudes, J. Geophys. Res., 78, 5597-5610, 1973.

Balan, N., Oyama, K. I., Bailey, G. J., and Abe, T.: Plasmasphere electron temperature studies using satellite observations and a theoretical model, J. Geophys. Res., 101, 15 323-15330, 1996 .

Balan, N., Oyama, K. I., Bailey, G. J., and Abe, T.: Plasmasphere electron temperature profiles and the effects of photoelectron trapping and an equatorial high altitude heat source, J. Geophys. Res., 101, 21 689-21 696, 1996b.

Balan, N., Oyama, K. I., Bailey, G. J., Fukao, S., Watanabe, S., and Abdu, M. A.: A plasma temperature anomaly in the equatorial topside ionosphere, J. Geophys. Res., 102, 7485-7492, 1997.

Bhuyan, P. K., Chamua, M., Subrahmanyam, P., and Garg, S. C.: Diurnal, seasonal and latitudinal variation of electron temperature measured by the SROSS C2 satellite at $\sim 500 \mathrm{~km}$ altitude and comparison with the IRI, Ann. Geophys., 20, 807-815, $2002 \mathrm{a}$.

Bhuyan, P. K., Kakoty, P. K., Garg, S. C., and Subrahmanyam, P.: Electron and ion temperature and electron density at $\pm 10^{\circ}$ magnetic latitudes from SROSS C2 measurements over India and comparison with the IRI, Adv. Space Res., 29(6), 865-870, 2002b. 
Bhuyan, P. K., Chamua, M., Subrahmanyam, P., and Garg, S. C.: Effect of solar activity on diurnal and seasonal variations of electron temperature measured by the SROSS C2 over Indian low latitudes, Adv. Space Res., 37, 885-891, 2006.

Brace, L. H. and Theis, R. F.: Global empirical models of ionospheric electron temperature in the upper $\mathrm{F}$ region and plasmasphere based on in situ measurements from the Atmospheric Explorer-C, ISIS-1 and ISIS-2 satellites, J. Atmos. Terr. Phys., 43, 1317-1343, 1981.

Brace, L. H., Reddy, B. M., and Mayr, H. G.: Global behaviour of the ionosphere at 1000 kilometre altitudes, J. Geophys. Res., 72, 265-583, 1967.

Brace, L. H., Chappell, C. R., Chandler, M. O., Comfort, R. H., Horwitz, J. L., and Hoegy W. R.: F-region electron temperature signatures of the plasmapause based on Dynamics Explorer 1 and 2 measurements, J. Geophys. Res., 93, 1896-1908, 1988.

Clark, D. H., Raitt, W. J., and Willmore, A. P.: The global morphology of electron temperature in the topside ionosphere as measured by ac Langmuir probe, J. Atmos. Terr. Phys., 34, 1765$1880,1972$.

Dalgarno, A. and McElroy, M. B.: Ionosphere electron temperature near dawn, Planet. Space Sci., 13, 143-145, 1965.

DaRosa, A. V.: The theoretical time dependent thermal behaviour of the ionosphere electron gas, J. Geophys. Res., 71, 4107-4120, 1966.

Evans, J. V.: Cause of the midlatitude evening increase in fof2, J. Geophys. Res., 70, 1175-1185, 1965.

Garg, S. C., Anand, J. R., Bahl, M., Subrahmanyam, P., Rajput, S. S., Maini, H. K., Chopra, P., John, T., Singhal, S. K., Singh, V., and Singh, D.: RPA aeronomy experiment onboard the Indian satellite SROSS C2 some important aspects of the payload and satellite, Indian J. Radio Space Phys., 32, 5-15, 2003.

Hanson, W. B., Naggy, A. F., and Moffett, R. J.: Ogo-6 measurements of super cooled plasma in the equatorial exosphere, J. Geophys. Res., 78, 751-756, 1973.

Mahajan, K. K. and Pandey, V. K.: Solar activity changes in the electron temperature at $1000 \mathrm{~km}$ altitude from the Langmuir probe measurements on ISIS and Explorers 22 satellites, J. Geophys. Res., 84, 5885-5889, 1979.

Mahajan, K. K.: Models of electron temperature in the ionospheric F-region using electron density height profiles, J. Atmos. Terr. Phys., 39, 637-639, 1977.

McClure, J. P.: Diurnal variation of neutral and charged particle temperatures in the equatorial F-region, J. Atmos. Terr. Phys., 74, 279-291, 1969.

McClure, J. P.: thermospheric temperature variation inferred from incoherent scatter observations, J. Geophys. Res., 76, 31063115,1971

Oliver, W. M., Takami, T., Fukao, S., Sato, T., Yamamoto, M., Thuda, T., Nakamura, T., and Kato, S.: Measurement of ionospheric and thermospheric temperatures and densities with the Middle and Upper Atmosphere radar, J. Geophys. Res., 96, $17827-17838,1991$.

Oyama, K. I., Abdu, M. A., Balan, N., Bailey, G. J., Watanabe, S., Takahashi, T., de Paula, E. R., Batista, I. S., Isoda, F., and Oya, H.: High electron temperature associated with the prereversal enhancement in the equatorial ionosphere, J. Geophys. Res., 102, 417-424, 1997.

Oyama, K. I., Balan, N., Watanabe, S., Takahashi, T., Isoda, F.,
Bailey, G. J., and Oya, H.: Morning overshoot of $T_{e}$ enhanced by downward plasma drift in the equatorial topside ionosphere, J. Geomagn. Geoelectr., 48, 959-966, 1996.

Oyama, K. I., Hirao, K., Banks, P. M., and Williamson, P. R.: Is $T_{e}$ equal to $T_{n}$ at the heights of $100-120 \mathrm{~km}$ ?, Planet. Space Sci. $28,207-211,1980$

Oyama, K. I., Marinov, P., Kutiev, I., and Watanabe, S.: Low latitude model of $T_{e}$ at $600 \mathrm{~km}$ based on Hinotori satellite data, Adv. Space Res., 34, 2004-2009, 2004.

Oyama, K. I.: Verification of IRI plasma temperature at great altitude by satellite data, Adv. Space Res., 12, 105-113, 1994.

Pandey, V. K. and Mahajan, K. K.: Solar activity control of F2 region electron temperature from incoherent scatter measurements at Millstone Hill, Indian J. Radio Space Phys., 14, 159-161, 1985.

Pavlov, A. V., Fukao, S., and Karwamura, S.: Comparison of the measured and modelled electron densities, and electron and ion temperatures in the low-latitude ionosphere during 12-21 March 1988, Ann. Geophys., 22, 2747-2763, 2004, http://www.ann-geophys.net/22/2747/2004/.

Raghavarao, R., Wharton, L. E., Spencer, N. W., Mayr, H. G., and Brace, L. H.: An equatorial temperature and wind anomaly (ETWA), Geophys. Res. Lett., 18, 1193-1196, 1991.

Richards, P. G. and Torr, D. G.: Thermal coupling of conjugate ionosphere and the tilt of the earth's magnetic field, J. Geophys. Res., 91, 9017-9025, 1986.

Schunk, R. W. and Nagy, N. F.: Electron temperatures in the F region of the ionosphere: theory of observation, Rev. Geophys. $16,355-399,1978$

Spenner, K. and Plugge, R.: Empirical model of global electron temperature distribution between 300 and $700 \mathrm{~km}$ based on data from AEROS-A, J. Geophys., 46, 42-52, 1979.

Su, Y. Z., Oyama, K. I., Bailey, G. J., Takahashi, T., and Watanabe, S.: Spatial and temporal variations of the electron temperature at equatorial anomaly latitudes, Adv. Space Res., 18, 83-86, 1996.

Su, Y. Z., Oyama, K. I., Bailey, G. J., Takahasi, T., and Watanabe, S.: Comparison of satellite electron density and temperature measurements at low latitudes with a plasmasphere ionosphere model, J. Geophys. Res., 100, 14 591-14 604, 1995.

Triskova, L., Smilaver, J., Truhlik, V., and Afonon, V. V.: On the low latitude topside models: II Electron temperature, Adv. Space Res., 18, 213-216, 1996.

Truhlik, V., Triskova, L., and Smilaver, J.: Improved electron temperature model and comparison with satellite data, Adv. Space Res., 27(1), 101-109, 2001.

Truhlik, V., Triskova, L., Smilaver, J., and Afonin, V.: Global empirical model of electron temperature in the outer ionosphere for period of high solar activity based on data of three Intercosmos satellites, Adv. Space Res., 25(1), 163-169, 2000.

Watanabe, S. and Oyama, K. I.: Dynamic model and observation of the equatorial ionosphere, Adv. Space Res., 15, 109-112, 1995.

Watanabe, S. and Oyama, K. I.: Effects of neutral wind on the electron temperature at a height of $600 \mathrm{~km}$ in the low-latitude region, Ann. Geophys., 14, 290-296, 1996, http://www.ann-geophys.net/14/290/1996/.

Watanabe, S., Oyama, K. I., and Abdu, M. A.: Computer simulation of electron and ion densities and temperatures in the equatorial F-region and comparison with Hinotori results, J. Geophys. Res., 100, 14 581-14 590, 1995. 